\title{
EFEK INTELECTUAL CAPITAL (IC) PADA MOTIVASI PERILAKU WINDOW DRESSING LAPORAN KEUANGAN PADA PERUSAHAAN TRANSPORTASI YANG TERDAFTAR DI BURSA EFEK INDONESIA
}

\author{
Heni Yusnita \\ Fakultas Ekonomi Universitas Krisnadwipayana \\ Jalan Unkris Jatiwaringin Jakarta Timur \\ Email: heniyusnita@unkris.ac.id
}

\begin{abstract}
The purpose of this study was to examine the effect of intellectual capital on the motivation for window dressing behavior in financial statements in transportation companies listed on the Indonesia Stock Exchange. This study uses primary data obtained by filling out a questionnaire. The population in this study are all transportation companies listed on the Indonesia Stock Exchange in 2021 as many as 47 companies with a sample of 20 companies. The data analysis technique used in this study uses Structural Equation Modeling (SEM) with Smart PLS (Partial Least Square) software. The results of the study: 1. Human capital has an effect on the motivation of window dressing behavior, 2. Structural capital has no effect on the motivation of window dressing behavior, 3. Relational capital has an effect on the motivation of window dressing behavior.
\end{abstract}

Keywords: Intellectual Capital, Human Capital. Structural Capital, Relational Capital, Window Dressing

\section{PENDAHULUAN}

Fraud dalam penyajian laporan informasi keuangan masih menjadi polemik bagi dunia industri di tanah air. Hal ini di karena adanya perilaku investor yang hanya melihat laba sebagai tolak ukur keberhasilan kinerja manajemen. Sehingga manajemen berupaya melakukan window dressing yang merupakan salah satu praktik dari earnings management ataupun melakukan hal yang paling ekstrem yaitu kecurangan dengan tujuan agar laba terlihat baik di mata para investor. Salah satu berita besar fraud pada tahun 2019 menimpa maskapai penerbangan terbesar di Indonesia "Garuda Indonesia". Semua berawal dari hasil laporan keuangan Garuda Indonesia untuk tahun buku 2018. Dalam laporan keuangan tersebut, Garuda Indonesia Group membukukan laba bersih sebesar USD809,85 ribu atau setara Rp11,33 miliar (asumsi kurs Rp14.000 per dolar AS). Angka ini melonjak tajam dibanding 2017 yang menderita rugi USD216,5 juta. Namun laporan keuangan tersebut menimbulkan polemik, lantaran dua komisaris Garuda Indonesia yakni Chairal Tanjung dan Dony Oskaria (saat ini sudah tidak menjabat), menganggap laporan keuangan 2018 Garuda Indonesia tidak sesuai dengan Pernyataan Standar Akuntansi Keuangan (PSAK). (Hartomo, 2019).

Selain PT Garuda, terdapat perusahaan-perusahaan besar yang juga terlibat dalam Tindakan fraud diantaranya Jiwasraya, Asabri, PT Angkasa Pura II dan PT Industri Telekomunikasi Indonesia.

Tindakan fraud tentunya membuat laporan keuangan yang diterima oleh para stakeholder menjadi tidak handal dan tidak relevan lagi untuk pengambilan keputusan dan sangat merugikan mereka. Pada akhirnya akan menghilangkan kepercayaan mereka pada perusahaan, sehingga menurunkan nilai perusahaan. Fraud dalam penyajian laporan keuangan berawal dari tindakan window dressing yang berkembang menjadi kecurangan yang menyesatkan secara material (Rezaee, 2005). Dechow et al, (1996) memberikan bukti bahwa perusahaan memilih melakukan fraud dalam pelaporan keuangan ketika mereka memiliki kesempatan untuk melakukan window dressing dengan dengan tujuan agar kinerja mereka terlihat sukses di depan para 
pemegang saham. Perusahaan sangat yakin bahwa kinerja mereka diukur dari kemampuan perusahaan menghasilkan laba.

\section{Informasi laba (returns)} merupakan salah satu sarana informasi penting di dalam laporan keuangan perusahaan yang berperan sebagai sinyal kinerja perusahaan, serta sangat dipengaruhi oleh sumber daya (resources) dan kemampuan (capabilities) yang dimiliki oleh perusahaan. Globalisasi dan inovasi teknologi memunculkan suatu pandangan baru dalam dunia bisnis yaitu kemakmuran suatu perusahaan akan bergantung pada penciptaan transformasi dan kapitalisasi dari pengetahuan, yang disebut intellectual capital/IC (modal intelektual). Chen et al., (2004) menyatakan ekonomi industri dengan fitur kombinasi optimal faktor produksi dan kekayaan ekonomi, yaitu aset berwujud dan fisik, telah memberikan tempat untuk ekonomi berbasis pengetahuan, sebagai faktor kunci, memainkan peran penting dalam menciptakan nilai dan kekayaan. Karena pada saat ekonomi berbasis pengetahuan, modal intelektual (intellectual capital) menjadi jauh lebih penting daripada modal yang disetor.

Intellectual capital menurut Bontis et al., (2000) yaitu mencakup semua pengetahuan karyawan, organisasi dan kemampuan mereka untuk menciptakan nilai tambah dan menyebabkan keunggulan kompetitif berkelanjutan. Semakin tinggi kemampuan intelektual yang dimiliki oleh manajer perusahaan, maka diduga semakin besar peluang terjadinya manajemen laba. Hal ini dikarenakan pengetahuan, keterampilan, dan kompetensi yang dimiliki manajer menghasilkan solusi terbaik untuk meningkatkan laba perusahaan, sehingga bonus yang diterima manajer juga akan meningkat.

Tujuan dari penelitian ini adalah untuk menguji pengaruh intellectual capital terhadap motivasi perilaku window dressing laporan keuangan pada perusahaan transportasi yang terdaftar di Bursa Efek Indonesia.

\section{LANDASAN TEORI}

\section{Teori Keagenan (Agency Theory)}

Ross, (1973) adalah orang pertama yang menyelidiki masalah keagenan, sementara Jensen, M. \& Meckling, (1976) adalah orang pertama yang menyajikan studi teoretis penuh tentang teori keagenan, mengacu pada manajer perusahaan sebagai "agen" dan pemegang saham sebagai "prinsipal". ." Manajer yang merupakan representasi atau agen pemegang saham mengalihdayakan pengambilan keputusan bisnis kepada pemegang saham yang menjadi prinsipal. Isu yang berkembang sebagai akibat dari sistem kepemilikan perusahaan adalah bahwa agen tidak selalu membuat keputusan demi kepentingan terbaik prinsipal. Karena manajer perusahaan cenderung mengejar tujuan pribadi, salah satu asumsi utama teori keagenan adalah bahwa tujuan prinsipal dan tujuan agen yang berbeda dapat menyebabkan konflik. Dengan berinvestasi dalam usaha jangka panjang yang menguntungkan, pemegang saham mendapat manfaat.

\section{Resource Based Theory}

Asumsi kunci dari pandangan teori berbasis sumber daya adalah bahwa organisasi dapat makmur jika memperoleh dan mempertahankan keunggulan kompetitif. Menerapkan pendekatan penciptaan nilai yang tidak dapat diduplikasi oleh pesaing dan tidak ada item pengganti yang dapat memberi Anda keunggulan kompetitif (Sirmon et al., 2007). Kompetensi utama perusahaan meliputi kemampuan yang bernilai (valuable), langka (langka), sulit untuk ditiru (mahal untuk ditiru), dan kemampuan yang tidak dapat digantikan (nonsubstitutable) (kompetensi inti). 
Keunggulan bersaing tidak akan bertahan lama jika salah satu dari keempat unsur tersebut tidak terpenuhi. Akibatnya, untuk mempertahankan keunggulan kompetitif jangka panjang, kompetensi perusahaan tidak dapat diduplikasi, dan item tidak memiliki pengganti dari perspektif konsumen. Panjang keunggulan kompetitif ditentukan oleh seberapa cepat pesaing dapat menyalin barang, jasa, atau proses. Hanya ketika keempat komponen ini terpenuhi, keunggulan kompetitif jangka panjang dapat dicapai.

\section{Knowledge Based Theory}

Skandia \& Ernst \& Young, (1998) menyoroti karakter statis pengetahuan, seperti inovasi, ide, program komputer, paten, dan bentuk kekayaan intelektual lainnya. Edvinsson \& Sullivan, (1996) sama-sama membahas sumber daya manusia, atau modal manusia, tetapi menggarisbawahi bahwa "jelas untuk keunggulan pengetahuan perusahaan untuk mengubah penemuan yang dihasilkan oleh sumber daya manusia menjadi intelektual aset, di mana perusahaan dapat mengklaim hak kepemilikan." Salah satu tanggung jawab utama manajer IC adalah mengubah sumber daya manusia menjadi aset intelektual.

\section{Intellectual Capital}

Modal intelektual (yang termasuk aset tidak berwujud) digambarkan sebagai aset non-fisik yang akan menguntungkan perusahaan di masa depan (Canibano, 2000 dalam Ahmad 2011). Menurut Gioacasi \& Diana, (2010), modal intelektual dipandang sebagai sumber daya perusahaan yang dapat digunakan untuk membentuk kesehatan perusahaan dan memberikan nilai. Modal manusia, modal struktural, dan modal pelanggan adalah tiga bagian dari modal intelektual yang umumnya diidentifikasi dalam proses klasifikasi (Edvinsson \& Malone M, 1997); (Sveiby, 1997). Ihyaul Ulum, (2015) mendefinisikan modal intelektual sebagai total nilai aset tidak berwujud, yang meliputi:

\section{a. Human Capital}

Keahlian, pengetahuan, dan kemampuan adalah contoh modal manusia. Modal manusia adalah jenis modal intelektual yang berhubungan dengan pengetahuan dan pengalaman manusia, dan memiliki dampak pada nilai perusahaan melalui mempengaruhi faktor-faktor lain. Kompetensi dan keahlian karyawan merupakan sumber penting dari inovasi organisasi (Wang \& Chang, 2005)

\section{b. Structural Capital}

Segala sesuatu yang dihasilkan oleh pegawai, seperti database, perangkat lunak, pedoman, struktur organisasi, dan sebagainya, disebut sebagai modal struktural. Menurut Bontis \& Fitz-enz, (2002) dan Daneshi, Ali \& Pirzad, (2013) , pusat pengetahuan dalam organisasi, termasuk teknologi, adalah modal struktural. Biasanya mengacu pada pengetahuan infrastruktur yang menjelaskan struktur organisasi, budaya, dan aspek teknologi (Ahmad \& Mushraf, 2001). Modal struktural, di sisi lain, didefinisikan oleh Daneshi, Ali \& Pirzad, (2013) sebagai "perangkat keras, perangkat lunak, database, struktur organisasi, paten, reputasi perusahaan, dan item lain yang digunakan personel perusahaan untuk mendukung operasi dan aktivitas bisnis perusahaan."

\section{c. Customer Capital}

Modal pelanggan adalah komoditas berharga yang ditunjukkan oleh reputasi perusahaan dan loyalitas pelanggan. Modal pelanggan adalah istilah yang mengacu pada sumber daya yang terkait dengan pelanggan. Modal pelanggan adalah jenis modal struktural yang dibentuk melalui hubungan dengan pelanggan. Modal 
pelanggan mengacu pada hubungan harmonis perusahaan dengan mitranya, termasuk pemasok yang dapat diandalkan dan berkualitas tinggi. Pelanggan yang loyal dan puas dengan layanan yang ditawarkan menghasilkan modal pelanggan, yang membuat mereka kembali ke perusahaan yang bersangkutan.

\section{Motivasi Window Dressing}

Sebelum membuat keputusan investasi, investor harus menilai kesehatan keuangan dan portofolio bisnis mereka. Akibatnya, sebuah korporasi bersaing dengan perusahaan lain untuk menampilkan wajah terbaiknya kepada investor melalui pendekatan window dressing. Laporan keuangan atau kinerja perusahaan, serta portofolio bisnisnya, dipercantik sebagai bagian dari rencana rias untuk menarik investor. Tentu saja, tujuannya adalah untuk membujuk investor agar mau menanamkan uangnya ke dalam investasi yang berhasil bagi perusahaan. Window dressing adalah proses membuat laporan keuangan perusahaan tampak lebih baik dari yang sebenarnya. Akibatnya, window dressing sering dikaitkan dengan konotasi negatif karena kemungkinan memanipulasi statistik, data, dan informasi yang dilaporkan dalam laporan keuangan.

Secara umum terdapat beberapa hal yang memotivasi individua tau badan usaha melakukan tindakan window dressing diantaranya : Motivasi bonus, motivasi utang dan motivasi pajak,

\section{Efek Intellectual Capital (IC) pada Motivasi Perilaku Window Dressing Laporan Keuangan}

Jika dibandingkan dengan modal intelektual (IC), peran dan nilai modal fisik dalam menciptakan keuntungan yang berkelanjutan secara substansial kurang (Taheri \& Assadollahi, 2013). Masalah utama dari penelitian ini adalah untuk menguji peran dan dampak dari modal intelektual dalam memprediksi laba masa depan perusahaan, di satu sisi, karena pentingnya prediksi laba akuntansi sebagai faktor yang mempengaruhi keputusan ekonomi pengguna, dan di sisi lain. Di sisi lain, karena pentingnya modal intelektual, sebagai bagian penting dari modal perusahaan secara keseluruhan, dalam mencapai laba yang berkelanjutan dan jangka panjang, dan kebutuhan untuk mengidentifikasi dampak modal intelektual dalam memprediksi laba masa depan perusahaan.

Dalam studi mereka, (Galdipour et al., 2014) menemukan bahwa Intellectual Capital/IC memiliki hubungan positif yang substansial dengan manajemen laba, menggunakan manajemen laba akrual sebagai proksi untuk manajemen laba. Dalam penelitiannya, Mojtahedi, (2013) menemukan bahwa Intellectual Capital/IC memiliki hubungan yang menguntungkan dengan kualitas laba yang diukur dengan manajemen laba akrual. Dalam studi mereka, Darabi et al., (2012) menemukan bahwa Intellectual Capital/IC memiliki hubungan positif dengan kualitas laba yang diukur dengan manajemen laba akrual (discretionary accruals). Akhirnya diputuskan bahwa IC memainkan fungsi yang baik dalam operasi perusahaan dan pelaporan keuangan.

Dalam penelitian ini Intelectual capital diproksikan dengan Human capital, Structural capital dan Relational capital.

Berdasarkan argumen di atas maka hipotesis penelitian ini adalah:

\section{H1: Human capital berpengaruh terhadap motivasi perilaku window dressing laporan keuangan}

$\mathrm{H}_{2}$ : Structural capital berpengaruh terhadap motivasi perilaku window dressing laporan keuangan

H3: Relational capital berpengaruh terhadap motivasi perilaku window dressing laporan keuangan 


\section{METODE PENELITIAN}

Penelitian ini menggunakan data primer yang diperoleh dengan melakukan pengisian kuesioner. Sasaran penelitian ini yaitu manajer perusahaan transportasi. Populasi dalam penelitian ini adalah seluruh perusahaan transportasi yang terdaftar di Bursa Efek Indonesia tahun 2021 sebanyak 47 perusahaan. Teknik analisis data yang digunakan dalam penelitian ini menggunakan Structural Equation Modelling (SEM) dengan software Smart PLS (Partial Least Square). Dalam PLS Path Modelling terdapat 2 model yaitu outer model dan Inner model.

\section{HASIL PENELITIAN DAN PEMBAHASAN}

Dari 47 kuesioner yang disebar, sebanyak 20 kuesioner yang dikembalikan, sehingga data yang diolah hanya 20 .

\section{A. Perancangan Model Struktural (Inner Model)}

Gambar 1. Perancangan model structural

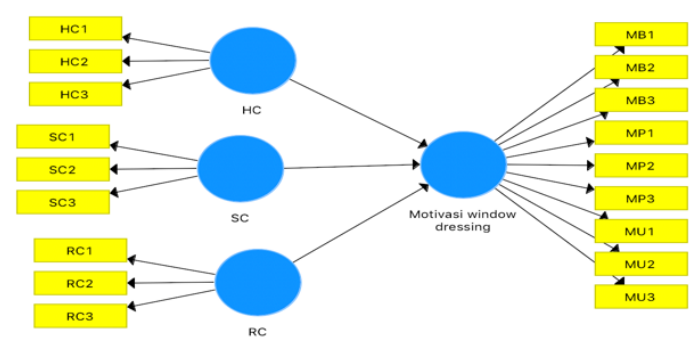

Keterangan :

HC : Human Capital

SC : Structural Capital

RC : Relational Capital

MB : Motivasi Bonus

MP : Motivasi Pajak

MU : Motivasi Utang

\section{Evaluasi Outer Model}

Convergent Validity

Korelasi antar skor indicator dengan skor konstruknya. Dalam model PLS memenuhi Convergent Validity dapat dikatakan valid apabila nilai loading 0,5 hingga 0,6 (Ghozali, 2011). Adapun hasil korelasi antara indikator dengan konstruknya seperti terlihat ada output di bawah ini:

Tabel 1. Hasil outer loading

\begin{tabular}{|l|l|l|l|l|}
\hline & HC & $\begin{array}{c}\text { Motivasi } \\
\text { Window } \\
\text { Dressing }\end{array}$ & RC & SC \\
\hline HC1 & 0,885 & & & \\
\hline HC2 & 0,585 & & & \\
\hline HC3 & 0,808 & & & \\
\hline MB1 & & 0,837 & & \\
\hline MB2 & & 0,857 & & \\
\hline MB3 & & 0,867 & & \\
\hline MP2 & & 0,512 & & \\
\hline MP3 & & 0,698 & & \\
\hline MU1 & & 0,813 & & \\
\hline MU2 & & 0,765 & & \\
\hline MU3 & & 0,726 & & \\
\hline RC1 & & & 0,835 & \\
\hline RC2 & & & 0,880 & \\
\hline RC3 & & & 0,801 & \\
\hline SC1 & & & & 0,959 \\
\hline SC2 & & & & 0,840 \\
\hline SC3 & & & & 0,959 \\
\hline
\end{tabular}

Gambar 2. Output Loading Factor Pemodelan

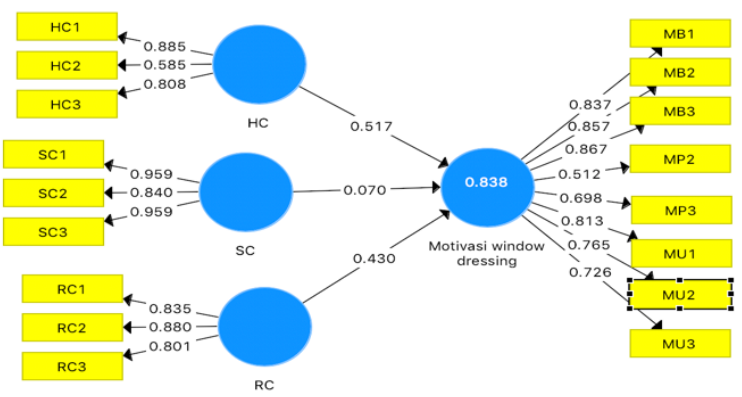


Menurut Ghozali, (2011), suatu korelasi dapat dikatakan memenuhi validitas konvergen apabila memiliki nilai loading factor sebesar lebih besar ari 0,5. Output menunjukkan bahwa loading factor memberikan nilai di atas nilai yang disarankan yaitu sebesar 0,5. Sehingga indikator-indikator yang dipergunakan dalam penelitian ini telah memenuhi validitas konvergen (Convergent validity).

\section{Uji validitas diskriminan}

Pada indikator reflektif perlu dilakukan pengujian validitas diskriminan (discriminant validity) dengan membandingkan nilai pada tabel cross loading. Suatu indikator dinyatakan valid jika mempunyai nilai loading factor tertinggi kepada konstruk yang dituju dibandingkan nilai loading factor kepada konstruk lain.

Tabel. 2. Output Cross Loading

\begin{tabular}{|l|l|l|l|l|}
\hline & HC & MWD & RC & SC \\
\hline HC1 & 0,808 & 0,703 & 0,551 & 0,293 \\
\hline HC2 & 0,585 & 0,472 & 0,401 & 0,469 \\
\hline HC3 & 0,808 & 0,736 & 0,626 & 0,210 \\
\hline MB1 & 0,569 & 0,837 & 0,772 & 0,568 \\
\hline MB2 & 0,648 & 0,857 & 0,674 & 0,407 \\
\hline MB3 & 0,848 & 0,867 & 0,707 & 0,504 \\
\hline MP2 & 0,618 & 0,512 & 0,311 & 0,300 \\
\hline MP3 & 0,483 & 0,698 & 0,710 & 0,668 \\
\hline MU1 & 0,754 & 0,813 & 0,580 & 0,414 \\
\hline MU2 & 0,603 & 0,765 & 0,704 & 0,342 \\
\hline MU3 & 0,621 & 0,726 & 0,627 & 0,349 \\
\hline RC1 & 0,645 & 0,664 & 0,835 & 0,745 \\
\hline RC2 & 0,579 & 0,729 & 0,880 & 0,485 \\
\hline RC3 & 0,530 & 0,718 & 0,801 & 0,600 \\
\hline SC1 & 0,345 & 0,547 & 0,715 & 0,959 \\
\hline SC2 & 0,429 & 0,507 & 0,571 & 0,840 \\
\hline SC3 & 0,310 & 0,553 & 0,703 & 0,959 \\
\hline
\end{tabular}

\section{Uji Reliabilitas}

Sarwono \& Narimawati, (2015) menyatakan bahwa suatu variabel laten dapat dikatakan mempunyai realibilitas yang baik apabila nilai composite reliability lebih besar dari 0,7 dan nilai Cronbach's alpha lebih besar dari 0,7 .

Tabel. 3 Hasil Uji Reliabilitas Variabel Laten

\begin{tabular}{|l|l|l|l|}
\hline Konstrak & $\begin{array}{l}\text { Cronbach's } \\
\text { Alpha }\end{array}$ & $\begin{array}{l}\text { Composite } \\
\text { Reliability }\end{array}$ & Keterangan \\
\hline HC & 0,646 & 0,810 & Reliabel \\
\hline SC & 0,909 & 0,944 & Reliabel \\
\hline RC & 0,790 & 0,877 & Reliabel \\
\hline MWD & 0,898 & 0,918 & Reliabel \\
\hline
\end{tabular}

Tabel 3 menunjukan bahwa seluruh variabel-variabel laten yang diukur dalam penelitian ini memiliki nilai Cronbach's Alpha dan Composite Reliability yang lebih besar dibandingkan dengan 0,7 sehingga dapat dikatakan bahwa semua variabel laten reliabel. Nilai Cronbach's Alpha untuk variabel HC sebesar 0,646 lebih kecil dari 0,7. Ini dianggap reliabel karena mendekati 0,7.

\section{Evaluasi Model Struktural (Inner Model)}

Evaluasi model struktural pada SEM dengan PLS dilakukan dengan melakukan uji R-squared $\left(\mathrm{R}^{2}\right)$ dan uji signifikansi melalui estimasi koefisien jalur.

\section{Pengujian $\mathbf{R}^{2}$}

Output untuk nilai $\mathrm{R}^{2}$ menggunakan program komputer smartPLS 3.0 diperoleh: Tabel. 4. Output Perhitungan $\mathrm{R}^{2}$

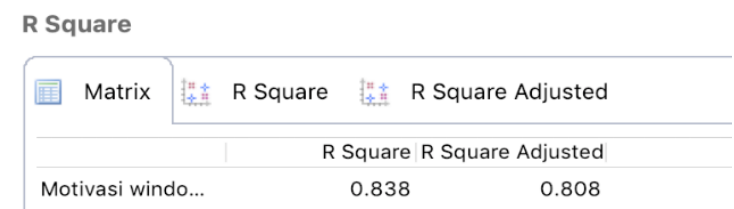

Nilai $R$-squared $\left(\mathrm{R}^{2}\right)$ dipergunakan untuk megukur seberapa besar pengaruh variabel laten independen tertentu terhadap 
variabel laten dependen. Menurut (Ghozali, 2011), hasil $\mathrm{R}^{2}$ sebesar 0,67 mengindikasikan bahwa model dikategorikan baik. Tabel 4 menunjukan nilai $\mathrm{R}^{2}$ penelitian ini sebesar 0.838 yang berarti memiliki nilai lebih besar dari 0.67. Maka dapat dikatakan pemodelan yang dibentuk dikategorikan sebagai model yang baik.

\section{Uji Signifikansi}

Uji signifikansi pada model SEM dengan PLS bertujuan untuk mengetahui pengaruh variabel eksogen terhadap variabel endogen. Pengujian hipotesis dengan metode SEM PLS dilakukan dengan cara melakukan proses bootstrapping dengan bantuan program komputer smartPLS 3.0 sehingga diperoleh hubungan pengaruh variabel eksogen terhadap variabel endogen sebagai berikut:

Tabel 5. Hasil Perhitungan Bootstrapping Data Penelitian

\begin{tabular}{|l|c|c|c|c|c|}
\hline & $\begin{array}{c}\text { Original } \\
\text { Sample } \\
\text { Estimate } \\
(\mathbf{O})\end{array}$ & $\begin{array}{c}\text { Sample } \\
\text { Mean } \\
(\mathbf{M})\end{array}$ & $\begin{array}{c}\text { Standard } \\
\text { Deviation } \\
\text { (STD) }\end{array}$ & $\begin{array}{c}\text { T Statistcs } \\
\text { (IO/STDEVI) }\end{array}$ & $\begin{array}{c}\text { P } \\
\text { Values }\end{array}$ \\
\hline $\begin{array}{l}\text { HC-> } \\
\text { Motivasi } \\
\text { window } \\
\text { dressing }\end{array}$ & 0,517 & 0,507 & 0,176 & 2,936 & 0,003 \\
\hline $\begin{array}{l}\text { SC-> } \\
\begin{array}{l}\text { Motivasi } \\
\text { window } \\
\text { dressing }\end{array}\end{array}$ & 0,070 & 0,076 & 0,173 & 0,404 & \\
\hline $\begin{array}{l}\text { RC-> } \\
\text { Motivasi } \\
\text { window } \\
\text { dressing }\end{array}$ & 0,430 & 0,438 & 0,203 & 2,114 & 0,686 \\
\hline
\end{tabular}

Sebelum dilakukan pengujian hipotesis, diketahui bahwa nilai nilai $\mathrm{T}$-tabel untuk tingkat kepercayaan sebesar 95\% ( $\alpha$ sebesar $5 \%$ ) dan derajat kebebasan (df) $=\mathrm{n}-2=20$ $-2=18$ adalah sebesar 2,100. Pengujian hipotesis untuk masing-masing hubungan variabel laten ditunjukan sebagai berikut:
a. Pengujian
Hipotesis
Variabel

Pengaruh Human capital $\left(\mathrm{X}_{1}\right)$ terhadap

Variabel Motivasi perilaku window dressing laporan keuangan (Y)

$\begin{array}{ll}\mathrm{H}_{01} & \mathrm{X}_{1} \rightarrow X^{\prime} \\ \mathrm{H}_{11} & \mathrm{X}_{1} \rightarrow \mathrm{Y}\end{array}$

Berdasarkan hasil output Tabel 5, T statistik untuk variabel Pengaruh
Human capital $\left(\mathrm{X}_{1}\right)$ terhadap variabel Motivasi perilaku window dressing (Y) sebesar 2,936 > T-tabel $(2,100)$. Nilai original sample estimate menunjukan nilai positif sebesar 0,517 yang menunjukan bahwa arah hubungan variabel Pengaruh Human capital $\left(\mathrm{X}_{1}\right)$ terhadap variabel Motivasi perilaku window dressing laporan keuangan $(\mathrm{Y})$ adalah positif. Dengan demikian $\mathrm{H}_{1}$ pada penelitian diterima. Artinya, dalam penelitian ini variabel laten Pengaruh Human capital $\left(\mathrm{X}_{1}\right)$ dengan indikator-indikatornya berpengaruh terhadap variabel laten Motivasi perilaku window dressing laporan keuangan (Y) dengan indikatorindikatornya secara signifikan.

b. Pengujian Hipotesis Variabel Pengaruh Structural capital (X2) terhadap Variabel Motivasi perilaku window dressing laporan keuangan (Y)

$\mathrm{H}_{02} \quad \mathrm{X}_{2} \rightarrow \mathrm{Y} /$

$\mathrm{H}_{12} \quad \mathrm{X}_{2} \rightarrow \mathrm{Y}$

Berdasarkan hasil output pengolahan data pada Tabel $5 \mathrm{~T}$ statistik untuk variabel Structural capital $\left(\mathrm{X}_{2}\right)$ terhadap variabel Motivasi perilaku window dressing laporan keuangan $(\mathrm{Y})$ sebesar $0,404<$ T-tabel $(2,100)$. Dengan demikian $\mathrm{H}_{2}$ ditolak sehingga variabel laten structural capital $\left(\mathrm{X}_{2}\right)$ dengan indikator-indikatornya tidak berpengaruh terhadap variabel laten Motivasi perilaku window dressing laporan keuangan (Y) dengan indikator - indikatornya secara signifikan.

c. Pengujian Hipotesis Variabel Relational capital $\left(\mathrm{X}_{3}\right)$ terhadap Variabel Motivasi perilaku window dressing laporan keuangan (Y)

$\mathrm{H}_{03} \quad \mathrm{X}_{3} \rightarrow \mathrm{Y}$

$\mathrm{H}_{13} \quad \mathrm{X}_{3} \rightarrow \mathrm{Y}$

Berdasarkan hasil output pengolahan data pada Tabel 5, $\mathrm{T}$ statistik untuk variabel Relational capital $\left(\mathrm{X}_{3}\right)$ terhadap variabel Motivasi perilaku window dressing laporan keuangan (Y) 
sebesar 2,114 > T-tabel (2,100). Nilai original sample estimate menunjukan nilai positif sebesar 0,430 yang menunjukan bahwa arah hubungan variabel Relational capital $\left(\mathrm{X}_{3}\right)$ terhadap variabel Motivasi perilaku window dressing laporan keuangan $(\mathrm{Y})$ adalah positif. Dengan demikian $\mathrm{H}_{3}$ pada penelitian diterima. Artinya, dalam penelitian ini variabel laten Relational capital (X3) dengan indikator-indikatornya berpengaruh terhadap variabel laten Motivasi perilaku window dressing laporan keuangan (Y) dengan indikatorindikatornya secara signifikan.

Diperoleh nilai original sample estimate tertinggi yang mempengaruhi Motivasi perilaku window dressing laporan keuangan (Y) adalah pada variabel Pengaruh Human capital $\left(\mathrm{X}_{1}\right)$ sebesar 0,517. Hal ini menunjukan bahwa variabel Pengaruh Human capital (X1) memiliki pengaruh yang lebih tinggi dibandingkan variabel Relational capital (X3) secara langsung terhadap variabel Motivasi perilaku window dressing laporan keuangan (Y). Sementara variabel Structural capital (X2) dikatakan tidak berpengaruh terhadap Motivasi perilaku window dressing laporan keuangan (Y).

\section{KESIMPULAN DAN SARAN}

Berdasarkan hasil penelitian yang telah dilakukan maka dapat ditarik kesimpulan sebagai berikut :

1. Berdasarkan menggunakan metode Partial Least Square (PLS) pada perhitungan koefisien jalur dihasilkan pengaruh Human Capital dan Relational Capital terhadap motivasi perilaku window dressing adalah berpengaruh positif, ini membuktikan bahwa semakin tingginya Human Capital dan Relational Capital yang dimiliki oleh perusahaan akan berpengaruh terhadap terjadinya perilaku window dressing laporan keuangan.

2. Secara keseluruhan hasil penelitian ini mendukung teori resource based dan teori knowledge based. Perusahaan bersaing dengan perusahaan lain untuk mendapatkan keunggulan kompetitif dalam mengelola sumber daya yang dimilikinya sesuai dengan kemampuan perusahaan, diantara sumber daya tersebut adalah modal sumber daya manusia berupa pengetahuan, pengalaman dan wawasan. Perusahaan yang memiliki modal intelektual besar secara logika memiliki keuntungan kompetitif pada sumber daya manusianya. Dengan keunggulan kompetitif ini, mereka dengan mudah melakukan pengelolaan laba yang dilaporkan yang kemudian pada akhirnya mempengaruhi kinerja pasar perusahaan mendatang. Kondisi ini terjadi karena pelaku pasar cenderung langsung merespon informasi laba dibandingkan merespon informasi tentang modal intelektual.

3. Keterbatasan penelitian adalah pada jenis sampel yang terbatas. Karena itu penelitian mendatang menambah jumlah sampel penelitian yang digunakan.

\section{Saran}

Dilakukan penelitian dengan
metode penelitian triangulasi yang
merupakan gabungan metode kuantitatif
dan kualitatif secara bersamaan (Denzin
dan Lincoln, 2000) agar memberikan hasil
yang optimal.

\section{DAFTAR PUSTAKA}

Ahmad, S. bin, \& Mushraf, A. M. (2001). The Relationship Between Intellectual Capital and Business Performance: An Empirical Study in Iraq Industry. 

Volume 9 Nomor 1 (Januari - April) 2022

Bontis, N., \& Fitz-enz, J. (2002). Intellectual capital ROI: a causal map of human capital antecedents and consequents. Journal of Intellectual Capital, 3(3), 223-247. http://dx.doi.org/10.1108/1469193021 0435589

Bontis, N., William Chua Chong, K., \& Richardson, S. (2000). Intellectual capital and business performance in Malaysian industries. Journal of Intellectual Capital, 1(1), 85-100. https://doi.org/10.1108/14691930010 324188

Chen, Jin, Zhu, Z., \& Hong Yuan Xie. (2004). Measuring Intellectual Capital : A New Model and Empirical Study. Journal of Intellectual Capital, 2 no. 3, 225-235.

Daneshi, Ali, I. B. M., \& Pirzad, A. (2013). The Study of the Relationship Between Intellectual Capital and Financial Performance of the Listed Companies in Tehran Stock Exchange. Research Journal of Applied Science, Engineering and Technology, 6 (10), 1703-1710.

Darabi, R., Rad, K., \& Ghadiri, M. (2012). The relationship between Intellectual Capital and Earnings Quality. Research Journal of Applied Science, Engineering and Technology, 4 (20), 4192-4199.

Dechow. (1996). Causes And Consequences Of Earnings Manipulation: Analysis of Firm Subject to Enforcement Actions by The SEC,. Contemporary Accounting Research, 1-36.

Edvinsson, L., \& Malone M, S. (1997). Intellectual Capital - the Proven Way to Establish Your Company's Real Value by Measuring Its Hidden Brainpower. HarperBusiness.

Edvinsson, L., \& Sullivan, P. (1996). Developing a Model for Managing Intellectual Capital. European Management Journal, 14, 356-364.

Galdipour, S., Rahimiyan., F., Adeleh Etemad, \& Panahi, H. (2014).
Earnings Management And Intellectual Capital. Journal of Educational and Management Studies, 4 (2), 425-428.

Ghozali, I. (2011). Aplikasi Analisis Multivariate Dengan Program SPSS. Badan Penerbit Universitas Diponegoro.

Gioacasi, \& Diana. (2010). Intellectual Capital: A Critical Approach on Definitions and Categorization. CES Working Papers, VI(4).

Hartomo, G. (2019). Kronologi Kasus Laporan Keuangan Garuda Indonesia hingga Kena Sanksi. Okefinance. https://economy.okezone.com/read/20 19/06/28/320/2072245/kronologikasus-laporan-keuangan-garudaindonesia-hingga-kena-sanksi

Ihyaul Ulum. (2015). Intellectual capital : model pengukuran, framework pengungkapan dan kinerja organisasi. Universitas Muhammadiyah Malang.

Jensen, M., C., \& Meckling, W. (1976). "Theory of the firm: Managerial behavior, agency cost and ownership structure. Journal of Finance Economic, 3, 305-360,.

Mojtahedi, P. (2013). The Impact of Intellectual Capital on Earning Quality: Evidence from Malaysian Firm. Australian Journal of Basic And Applied Science, 7 (2), 535-540.

Rezaee, Z. (2005). Causes, consequences, and deterence of financial statement fraud. Critical Perspectives on Accounting, 16, 277-298.

Ross, S. (1973). The Economic Theory of Agency: The Principal's Problem. American Economic Review, 63, 134139.

Sarwono, J., \& Narimawati. (2015). Membuat Skripsi, Tesis dan Disertasi dengan Partial Least Square SEM (PLS-SEM). ANDI.

Sirmon, D. G., Hitt, M. A., \& Ireland, R. D. (2007). Managing firm resources in dynamic environments to create value: Looking inside the black box. Academy of Management Review, 
32(1), 273-292.

Skandia, \& Ernst \& Young. (1998). Intellectual Capital and Knowledge Management.

Sveiby, K. . (1997). he New Organizational Wealth: Managing and Measuring Knowledge-basedAssets. BerrettKoehler Publishers.

Taheri, F., \& Assadollahi, S. (2013). Examine the relationship between intellectual capital and stability of earnings in companies listed on the Tehran Stock Exchange. Dvances in Environmental Biology, 7 (10), 30853092.

Wang, W.-Y., \& Chang, C. (2005). Intellectual Capital and Performance in Causal Models Evidence from the Information Technology Industry in Taiwan. Journal of Intellectual Capital, 6, 222-236. https://doi.org/10.1108/14691930510 592816 
Printed ISSN : 2406-7415 Elektronik ISSN : 2655-9919

Jurnal Akuntansi dan Bisnis Krisnadwipayana Volume 9 Nomor 1 (Januari - April) 2022 